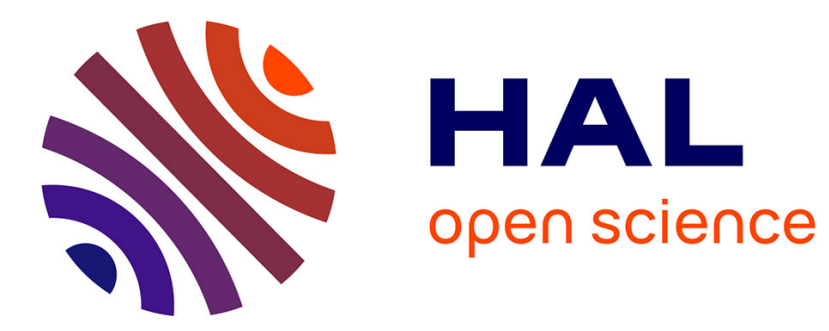

\title{
Modelling heat and mass transfer in solar evaporation systems
}

\author{
R. Fillet, V. Nicolas, V. Fierro, A. Celzard
}

\section{To cite this version:}

R. Fillet, V. Nicolas, V. Fierro, A. Celzard. Modelling heat and mass transfer in solar evaporation systems. International Journal of Heat and Mass Transfer, In press, 181, pp.121852. 10.1016/j.ijheatmasstransfer.2021.121852 . hal-03450059

\section{HAL Id: hal-03450059 \\ https://hal.univ-lorraine.fr/hal-03450059}

Submitted on 25 Nov 2021

HAL is a multi-disciplinary open access archive for the deposit and dissemination of scientific research documents, whether they are published or not. The documents may come from teaching and research institutions in France or abroad, or from public or private research centers.
L'archive ouverte pluridisciplinaire HAL, est destinée au dépôt et à la diffusion de documents scientifiques de niveau recherche, publiés ou non, émanant des établissements d'enseignement et de recherche français ou étrangers, des laboratoires publics ou privés.

\section{(1) (1) $\$$}

Distributed under a Creative Commons Attribution - NonCommercial - NoDerivatives 44.0 
8 *Corresponding Author: vincent.nicolas@univ-lorraine.fr

9 * Corresponding Author: alain.celzard@univ-lorraine.fr 


\section{Abstract}

A two-dimensional axisymmetric model of a solar evaporator was developed, based on a rigid biosourced open-cell foam floating on the surface of water contained in a beaker, including a set of boundary conditions and water transport in the porous medium. Experiments were carried out to validate the model for two cases, with and without a layer of 16 insulating material around the beaker. Several concrete cases of experimental solar evaporation studies recently reported in the literature, with or without insulation, radiation intensification, etc., have then been studied in the light of our model. We have thus been able to compare the observed trends with those of the numerical model in order to explain the results reported in the literature and, in some cases, to find a geometric optimum. The effect

21 of ambient conditions on the evaporation rate was investigated, and significant changes were observed by modifying solar input, air temperature and air humidity. We also showed that increasing the evaporation area and using an insulating layer between the water and the evaporative material increases the evaporation performance.

Keywords: Simulation, Biosourced material, Solar energy, Solar evaporation, Porous media, 


\section{Introduction}

In modern society, energy plays a major role, and its development as we know it today is only possible with access to a significant amount of resources. Nowadays, improving the effectiveness of systems and producing energy from more sustainable sources is more relevant than ever. Water evaporation, for example, is a subject of great interest [1] and a wide variety of materials have recently been developed to produce clean water from any source, even polluted water and seawater, without the need for an energy grid. Evaporation indeed occurs with or without solar flux at the water surface, but it can be enhanced by adding a floating porous medium.

Water evaporation systems (WESs) are composed of one or more materials, sometimes synthesised or manufactured from a natural resource, whose characteristics can be modified to improve evaporation efficiency [2]. In general, studies aim to improve materials properties, e.g. to increase the absorption of sunlight, to improve the energy conversion of light into heat or to improve the transport of water to the surface. Thermal conductivity can also be modified to reduce transfer to bulk water and thus conserve energy at the surface where evaporation occurs. In addition, the resistance of materials to clogging has been studied in seawater evaporation processes, where salt can affect long-term performance [3]. Changes in geometry have also been made to exploit heat exchange from the air to the surface instead of letting the transfer occur from the hot evaporation surface to the air [4].

Besides the large variability of solar evaporation systems mentioned above, a common problem encountered when reading the literature is that the protocol for measuring experimental performance is not identical in all publications. For example, some studies report mass loss measurements under a transparent bell jar and others do not. The bell jar has the effect of increasing the temperature and humidity of the air around the material compared to an open air system. In addition, tests can be carried out in different locations around the 
world with different humidity and temperature conditions. In some cases, an insulating layer can be used to support the evaporation material, which would not necessarily be able to float on its own, and to provide thermal insulation with the bulk water. Examples of such a system have been published based on pomelo peal [5] or plant stems [6]. All of these differences lead to more or less favourable conditions for the evaporation of water, regardless of the material.

The interest in proposing a numerical model that takes into account the mass and heat transfer that underlies water evaporation is the ability to accurately capture the behaviour of such WESs, and to explore the effect of experimental parameters such as those presented above. Whether it is the layout of the system, the geometry of the material or even the properties of the water within the material, it is possible to examine all of these impacts on the overall performance and behaviour in order to better understand how to design an efficient evaporation system. Furthermore, although numerical simulations have been used in the past for solar evaporation systems, they were limited to predicting certain aspects such as temperature distribution or water diffusion [7-9]. As far as we know, a general model taking into account the different types of heat exchange between the system and the air, the transport of water in the material and the evaporation from the water surface is missing in the literature.

In this work, we developed a model based on experimental results obtained under strictly controlled conditions, using a mimosa tannin foam that we have synthesised and used to improve water evaporation. Two cases were experimented, with and without insulation around the vessel containing the water to be evaporated, to limit heat exchange at the boundaries. These two cases were simulated, as the physics at the boundaries are different, and were validated using the same model apart from the system geometry and a few parameters. Various cases from the open literature have also been considered, allowing the effects of various operating conditions and materials geometry to be explored, and to which our model has been applied. Although the results between the literature experiments and our 
simulations cannot be directly compared due to the different materials used, the main trends could be successfully compared.

Therefore, our model should be particularly interesting in revealing the optimal geometry parameters, such as the dimensions of the insulation to be used beneath a material, or to study the impact of the insulation provided by synthetic foams used to allow the flotation of the material. Prior to our research, a guideline for the main experimental conditions, such as ambient temperature, relative humidity, geometry or position of the different elements, had been discussed [10]. Here, these conditions are investigated to describe their impact on the final evaporation rate and efficiency results, as our model takes into account the ambient air temperature, relative air humidity, air convection type and solar flux.

\section{Materials and Methods}

\subsection{Evaporation material}

Firstly, a bio-based foam was prepared, from which water evaporation experiments were conducted to validate our model. This foam was synthesised from tannin, a natural extract from the bark of the mimosa tree (Acacia Mearnsii), using a process described elsewhere [11]. The material was obtained by physical foaming, which involves producing a gas in situ in a thermosetting resin during its polymerisation. Table $\mathbf{1}$ shows all the ingredients used in the process, indicating their relative amounts and their role in the formulation. Briefly, tannin is first dissolved in water under magnetic stirring and then mixed with furfuryl alcohol. Next, diethyl ether and a 37 wt. \% aqueous solution of formaldehyde are added and the mixture is carefully homogenised. Finally, a 65 wt. \% aqueous solution of para-toluenesulphonic acid (pTSA) is added under stirring, after which the mixture expands rapidly while polymerising at the same time. Once fully expanded and cured, the foam is dried at room temperature for one week; further details are given elsewhere [12]. The foam is then cut to the proper dimensions, as shown in Fig. 1 (about $58 \mathrm{~mm}$ in diameter and $15 \mathrm{~mm}$ thick). 
107 Table 1. Standard formulation of tannin-based foam.

\begin{tabular}{lll}
\hline Ingredients & Role in the formulation & Mass $(\mathbf{g})$ \\
\hline Mimosa tannin extract & Base of the resin & 60 \\
pTSA (65 wt. \% in water) & Acidic catalyst & 22 \\
Furfuryl alcohol & Co-monomer & 21 \\
Formaldehyde (37 wt. \% in water) & Crosslinker & 14.8 \\
Water & Solvent & 12 \\
Diethyl ether & Blowing agent & 6 \\
\hline
\end{tabular}

\subsection{Experimental protocol and measurement methods}

110 The experiment consists in illuminating a beaker (60 $\mathrm{mm}$ diameter), filled with tap water

111 and with the foam floating on the surface, with a solar light simulator (SOLAR LIGHT LS-

112 1000). The experimental setup is shown in Fig. 1. A Sartorius ENTRIS weighing scale

113 accurate to the milligram is used to measure the mass of the whole system, and it is thus

114 possible to determine the amount of evaporated water by difference. T-type thermocouples are

115 used to measure temperatures at the interface between the evaporation material and the water

116 on the one hand, and within the evaporation material on the other hand. A thermal camera

117 (OPTRIS PI) pointing at the surface of the evaporation material is used to measure its

118 temperature locally. Air temperature and relative humidity are measured using a sensor placed

119 in the room. To explore the effect of heat exchange from the sides, a second experiment was

120 also conducted with insulating foam around the beaker. Therefore, case 1 discussed below

121 will refer to the case without insulation and case 2 to the case with insulation. 


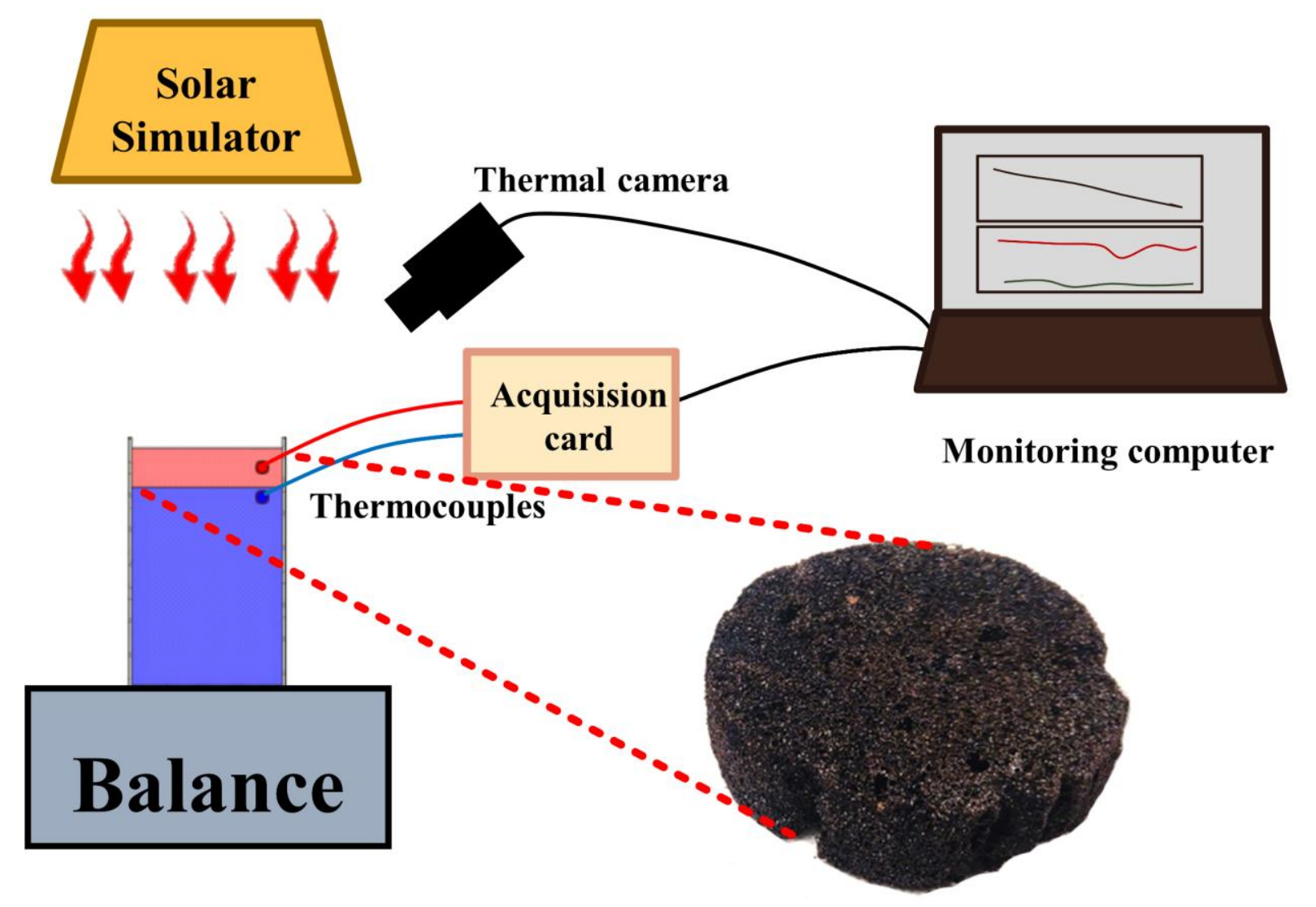

123 Fig. 1. Experimental setup used to measure the evaporation rate of water with a dark porous

124 foam floating on the surface. The $15 \mathrm{~mm}$-thick, $58 \mathrm{~mm}$ diameter tannin foam used for this

125 purpose is shown in the lower right-hand corner.

In order to compare it with the numerical model, the experiment was carried out under

127 three different solar concentrations: $0.7,1.0$ and 1.3 sun ( 1 sun being equal to $1 \mathrm{~kW} \mathrm{~m}^{-2}$ ) for

128 about one hour for each illumination. This allowed the evolution of heat and mass to be

129 studied as a function of solar concentration. The system efficiency was calculated using Eq. 1:

$$
\eta=\frac{\dot{m} h_{v}}{C_{o p t} P_{s, 0}}
$$

Eq. 1

130 where $\dot{m}\left(\mathrm{~kg} \mathrm{~m}^{-2} \mathrm{~h}^{-1}\right)$ is the evaporation rate, $C_{\text {opt }}$ (sun) is the solar concentration, and $P_{s, 0}$

$131\left(1000 \mathrm{~W} \mathrm{~m}^{-2}\right)$ is the power density of the average solar light on earth. Typical results in the

132 literature present the evaporation rate and efficiency for a given specific solar power.

133 Assuming a theoretical efficiency of $100 \%$ and with 1 sun illumination contributing only to 
134 the evaporation of water, whose enthalpy of vaporisation is $2450 \mathrm{~kJ} \mathrm{~kg}^{-1}$ under STP

135 conditions, $\dot{m}$ is equal to $1.47 \mathrm{~kg} \mathrm{~m}^{-2} \mathrm{~h}^{-1}$, which therefore represents the theoretical limit of

136 evaporation. Sometimes in the literature, evaporation in the dark is subtracted from the

137 evaporation rate with illumination to take into account only evaporation due to light. It is

138 useful to note that Eq. 1 does not take into account the heat exchange with the air, but only the

139 solar illumination input and the evaporation rate output. This is deliberate, as Eq. 1 is most

140 often used in the literature, and this is how we can compare our results with what has already

141 been published.

\section{Physical model}

143 A 2D axisymmetric model was written using COMSOL Multiphysics 5.6. Bulk water and

144 evaporation material were modelled as rectangles (in blue and red, respectively, in Fig. 2).

145 This basic geometry was adapted to cases 1 or 2 of the study, i.e., without or with an

146 insulating layer around the beaker, respectively. In this model, the upper surface is

147 illuminated by a solar radiation, is cooled by convection with air, and evaporates water. On

148 the sides and bottom, there are only convection and conduction, respectively. 
150 Fig. 2. Types of heat exchange at the boundaries of the system: (a) case 1: without insulation;

151 and (b) case 2: with insulation.

\subsection{General equations}

153 In order to simulate the heat and mass transfers existing during the evaporation process,

154 energy and mass conservation equations were used to obtain the temperature, $T$, (Eq. 2) and

155 the volume fraction of liquid in the pores, $\varepsilon_{l}$ (Eq. 3).

156 The conservation of energy equation describes conductive heat transfer and temperature

157 changes over time. The energy associated with mass transfer is small and due to the very slow

158 kinetics of this phenomenon, it has therefore been neglected in this study. This conservation

159 of energy equation is applied to calculate the temperature in the beaker and in the insulator

160 (corresponding to case 2).

$$
\rho_{j} c_{p, j} \frac{\partial T}{\partial t}+\vec{\nabla}\left(-\lambda_{j} \vec{\nabla} T\right)=0
$$

Eq. 2 
161 where $\rho_{j}\left(\mathrm{~kg} \mathrm{~m}^{-3}\right)$ is the density, $c_{p . j}\left(\mathrm{~J} \mathrm{~kg}^{-1} \mathrm{~K}^{-1}\right)$ is the heat capacity, and $\lambda_{j}\left(\mathrm{~W} \mathrm{~m}^{-1} \mathrm{~K}^{-1}\right)$ is the

162 thermal conductivity of component $\mathrm{j}$ (water $w$, evaporation material $m$ or insulating layer $i$ ).

163 The mass transfer is described by a phenomenon of water diffusion in the porous material 164 and is not solved in water or in the insulated medium. A transient equation is used in order to 165 allow the material to dry out and thus reduce surface evaporation when it is no longer 166 saturated. The equation is obtained by keeping the water liquid inside the material (Eq. 3).

$$
\rho_{w} \frac{\partial \varepsilon_{l}}{\partial t}+\vec{\nabla}\left(-D \frac{\varepsilon_{l} \rho_{w} \rho_{w}}{\varepsilon_{s} \rho_{s}} \vec{\nabla} \varepsilon_{l}\right)=0
$$

167 where $\varepsilon_{l}$ (dimensionless) is the water volume fraction in the evaporation material, $\varepsilon_{S}$ 168 (dimensionless) is its skeleton volume fraction, $\rho_{w}\left(\mathrm{~kg} \mathrm{~m}^{-3}\right)$ is the density of liquid water, $\rho_{s}$ $169\left(\mathrm{~kg} \mathrm{~m}^{-3}\right)$ is the skeleton density of the evaporation material, and $D\left(\mathrm{~m}^{2} \mathrm{~s}^{-1}\right)$ is the diffusion coefficient of water in the evaporation material.

\subsection{Boundary conditions}

In this section, the boundary conditions used are specified. It should be noted that thermal continuity conditions are used for the heat equation for all internal boundaries.

\subsubsection{Interface between the air and the material}

The heat exchange at the surface (Eq. 4) takes into account convection, incoming light radiation, as well as losses by emission and by water evaporation (Fig. 2). The latter involves the surface evaporation, $\dot{m}_{\text {surf }}\left(\mathrm{kg} \mathrm{m}^{-2} \mathrm{~h}^{-1}\right)$, multiplied by the energy consumed to raise the

178 temperature of water and the enthalpy of vaporisation of water, $h_{v}\left(\mathrm{~J} \mathrm{~kg}^{-1}\right)$.

$$
\begin{aligned}
-\vec{n}\left(-\lambda_{m} \vec{\nabla} T\right)= & h_{c}\left(T_{a}-T\right)+\dot{m}_{\text {surf }}\left(h_{v}+c_{p, w}\left(T_{w, i}-T\right)\right)+P_{s, 0} C_{o p t} \\
& +E_{m} \sigma\left(T_{a}{ }^{4}-T^{4}\right)
\end{aligned}
$$

179 with $\lambda_{m}\left(\mathrm{~W} \mathrm{~m}^{-1} \mathrm{~K}^{-1}\right)$ the thermal conductivity of the evaporation material, $h_{c}\left(\mathrm{~W} \mathrm{~m} \mathrm{~K}^{-1}\right)$ the

180 convection coefficient at the surface, $c_{p, w}\left(\mathrm{~J} \mathrm{~K}^{-1} \mathrm{~kg}^{-1}\right)$ the heat capacity of water, $T_{w, i}(\mathrm{~K})$ the

181 initial temperature of water, $P_{s, 0}\left(1000 \mathrm{~W} \mathrm{~m}^{-2}\right)$ the standard solar surface power, $C_{\text {opt }}$ (sun) 
the solar concentration (used to achieve different values of solar power), $E_{m}$ (dimensionless)

183 the emissivity of the material and $\sigma\left(5.67 \times 10^{-8} \mathrm{~W} \mathrm{~m}^{-2} \mathrm{~K}^{-4}\right)$ the Stefan-Boltzmann constant,

184 and $-\vec{n}$ the unit vector normal to the boundary.

185 To calculate the convective heat transfer coefficient, the following equation was used:

$$
h_{c}=\frac{\lambda_{\text {air }}}{L_{c}} N u
$$

186 where $L_{c}$ is the characteristic length of the surface (which corresponds to the diameter for the

187 top surface and the height for the side), and $N u$ is the Nusselt number (plane surface

188 assumption), which can be calculated as follows:

$$
N u_{\text {forced }, \text { top }}=0.3387 \frac{P_{r}^{\frac{1}{3}} R_{e^{\frac{1}{2}}}}{\left(1+\frac{0.0468^{\frac{2}{3}}}{P_{r}}\right)^{\frac{1}{4}}}
$$

189 In Eq. 6, Re is the Reynolds number and $\operatorname{Pr}$ the Prandtl number, such that:

$$
\operatorname{Pr}=\frac{\mu}{\alpha}
$$

190 in which $\alpha$ is the thermal diffusivity and $\mu$ the dynamic viscosity of the fluid, here the air. The

191 Reynolds number is calculated using the following equation:

$$
R e=\frac{u L_{c}}{v}
$$

192 with $u$ the velocity of air $\left(\mathrm{m} \cdot \mathrm{s}^{-1}\right)$ and $v$ is kinematic viscosity $\left(\mathrm{m}^{2} \cdot \mathrm{s}^{-1}\right)$.

193 Since $h_{c}$ is fitted for the case without any forced convection, the Nusselt number for the

194 case of natural convection, $N u_{\text {natural }}$, is determined using Eq. 5. Then, a Nusselt number

$195 N u_{\text {combined }}$, combination of both forced and natural convection, can be calculated [13]:

$N u_{\text {combined }}=\left(N u_{\text {natural }}^{4}+N u_{\text {forced }}^{4}\right)^{\frac{1}{4}}$

196 At the upper surface, the water loss in the diffusivity equation is equal to the evaporation

197 rate: 


$$
-\vec{n}\left(-D \frac{\varepsilon_{l} \rho_{w} \rho_{w}}{\varepsilon_{s} \rho_{s}} \vec{\nabla} \varepsilon_{l}\right)=\dot{m}_{\text {surf }}
$$

198 Finally, since water evaporation comes from the difference between the mass concentration of

199 the surface and the air, then $\dot{m}_{\text {surf }}$ is calculated as follows [14]:

$$
\dot{m}_{\text {surf }}=-k_{m} \frac{M}{R}\left(\frac{P_{w}^{v, s a t}}{T} a_{w}-H_{R} \frac{P_{a}^{v, s a t}}{T_{a}}\right)
$$

200 where $M\left(18 \times 10^{-3} \mathrm{~kg} \mathrm{~mol}^{-1}\right)$ is the molar mass of water, $R\left(8.314 \mathrm{~J} \mathrm{~mol}^{-1} \mathrm{~K}^{-1}\right)$ is the universal 201 gas constant, $P_{w}^{v, s a t}(\mathrm{~Pa})$ and $P_{a}^{v, \text { sat }}(\mathrm{Pa})$ are the water vapour pressures at the local 202 temperature $T(\mathrm{~K})$ and at the air temperature $T_{a}(\mathrm{~K})$, respectively, $a_{w}$ is the water activity, $H_{R}$

$203(\%)$ is the relative humidity and $k_{m}\left(\mathrm{~m} \mathrm{~s}^{-1}\right)$ is the convective mass exchange coefficient, 204 calculated using the Colburn analogy [13]:

$$
k_{m}=\frac{h_{c}}{1000}
$$

$205 P_{w}^{v, s a t}$ and $P_{a}^{v, s a t}$ are calculated from the Clapeyron formula as follows:

$$
P_{x}^{v, s a t}=P_{0} \exp \left(\frac{h_{v}}{R} M\left(\frac{1}{T_{0}}-\frac{1}{T}\right)\right)
$$

206 where $P_{x}^{v, \text { sat }}$ is the water vapour pressure at the temperature of the environment, $P_{0}$ is the 207 standard pressure of $101325 \mathrm{~Pa}$ and $T_{0}$ is the boiling point of water $(373.15 \mathrm{~K})$.

\subsubsection{Interface between the air and the side of the system}

Heat exchange between the air and the wall of the beaker involves convection and radiation losses:

$$
-\vec{n}\left(-\lambda_{j} \vec{\nabla} T\right)=h_{c, S}\left(T_{a}-T\right)+E_{S} \sigma\left(T_{a}{ }^{4}-T^{4}\right)
$$

211 where $\lambda_{j}\left(\mathrm{~W} \mathrm{~m}^{-1} \mathrm{~K}^{-1}\right)$ has the same meaning as in Eq. $1, h_{c, s}\left(\mathrm{~W} \mathrm{~m}^{-2} \mathrm{~K}^{-1}\right)$ is the convection 212 coefficient at the side, and $E_{s}$ (dimensionless) is the emissivity of the side.

213 For forced convection at the side of the system, the following Nusselt expression is used 214 assuming a vertical cylinder: 


$$
N u_{\text {forced }, \text { side }}=0.3+\frac{0,62 R_{e}{ }^{1 / 2} P_{r}{ }^{1 / 3}}{\left[1+\left(0,4 / P_{r}\right)^{\frac{2}{3}}\right]^{1 / 4}}\left[1+\left(\frac{R_{e}}{282}\right)^{5 / 8}\right]^{4 / 5}
$$

\subsubsection{Interface between the weighing scale and the bottom of the beaker}

At the interface between the weighing scale and the bottom of the beaker, only a

217 convective heat flow was assumed, formalised by:

$$
-\vec{n}\left(-\lambda_{w} \vec{\nabla} T\right)=h_{c, b}\left(T_{a}-T\right)
$$

218 where $h_{c, b}\left(\mathrm{~W} \mathrm{~m}^{-2} \mathrm{~K}^{-1}\right)$ is the convection coefficient at the bottom.

\subsubsection{Interface between the water and the evaporation material}

At the interface between the water and the evaporation material, as the latter is considered

222 is assumed, i.e.:

$$
\varepsilon_{l}=\varphi
$$

\subsection{Simulation parameters}

Table 2 lists the input parameters used in the simulation, and their symbols, definitions,

\begin{tabular}{|c|c|c|c|}
\hline Symbols & Definitions & Units & Values \\
\hline$\lambda_{w}, \lambda_{s}, \lambda_{a}, \lambda_{i}$ & $\begin{array}{l}\text { Thermal conductivities of water, skeleton of the } \\
\text { evaporation material, air, insulating material }\end{array}$ & $\mathrm{W} \mathrm{m^{-1 }} \mathrm{K}^{-1}$ & $\begin{array}{c}0.6,0.32 \\
0.0262,0.043\end{array}$ \\
\hline$\varphi$ & Porosity of the evaporation material & - & 0.955 \\
\hline$c_{p, w}, c_{p, s}, c_{p, i}$ & $\begin{array}{l}\text { Heat capacities of water, evaporation material } \\
\text { and insulating material }\end{array}$ & $\mathrm{J} \mathrm{K}^{-1} \mathrm{~kg}^{-1}$ & $4180,1800,871$ \\
\hline$D$ & $\begin{array}{l}\text { Coefficient of diffusion of water inside the } \\
\text { material }\end{array}$ & $\mathrm{m}^{2} \mathrm{~s}^{-1}$ & $10^{-8}$ \\
\hline$\rho_{w}, \rho_{s}, \rho_{i}$ & $\begin{array}{l}\text { Density of water, skeleton density of the } \\
\text { evaporation material, and bulk density of the } \\
\text { insulating material }\end{array}$ & $\mathrm{kg} \mathrm{m}^{-3}$ & $1000,1550,30$ \\
\hline
\end{tabular}

225 units and values considered are also given.

226 Table 2. Input parameters used in the simulation. 


$\begin{array}{lllc}\sigma & \text { Stefan-Boltzmann constant } & \mathrm{W} \mathrm{m}^{-2} \mathrm{~K}^{-4} & 5.67 \times 10^{-8} \\ R & \text { Universal gas constant } & \mathrm{J} \mathrm{mol}^{-1} \mathrm{~K}^{-1} & 8.314 \\ M & \text { Molar mass of water } & \mathrm{kg} \mathrm{mol} & 0.01801 \\ P_{0} & \text { Standard pressure } & \mathrm{Pa} & 101325 \\ T_{0} & \text { Boiling point of water } & \mathrm{K} & 373.15 \\ h_{c}, h_{c, s}, h_{c, b} & \begin{array}{l}\text { Heat transfer coefficients at the surface, the side } \\ \text { and the bottom }\end{array} & \mathrm{W} \mathrm{m}^{-2} \mathrm{~K}^{-1} & 5,5,1 \\ E_{m}, E_{S} & \begin{array}{l}\text { Emissivities of the material and of the side of the } \\ \text { beaker }\end{array} & - & 0.8,0.8 \\ & & & \end{array}$

\subsubsection{Water activity}

Fig. 3 shows the water activity, $a_{w}$, as a function of water uptake (wt.\%). $a_{w}$ was obtained

229 from the experimentally obtained moisture sorption isotherm, taken from a previous study

230 [15], and corresponds to the partial vapour pressure of water divided by the standard vapour 231 pressure of water. From the knowledge of the moisture content inside the material, it was 232 possible to obtain the partial vapour pressure of water with the water activity, and thus to 233 calculate the evaporation rate using Eq. 11. Since the evaporation rate is related to the amount 234 of water at the surface, the WES performance is limited if there is not enough water at the 235 surface. At $31 \%$ water uptake, the water activity is 1 , and remains constant for higher water 236 uptakes.

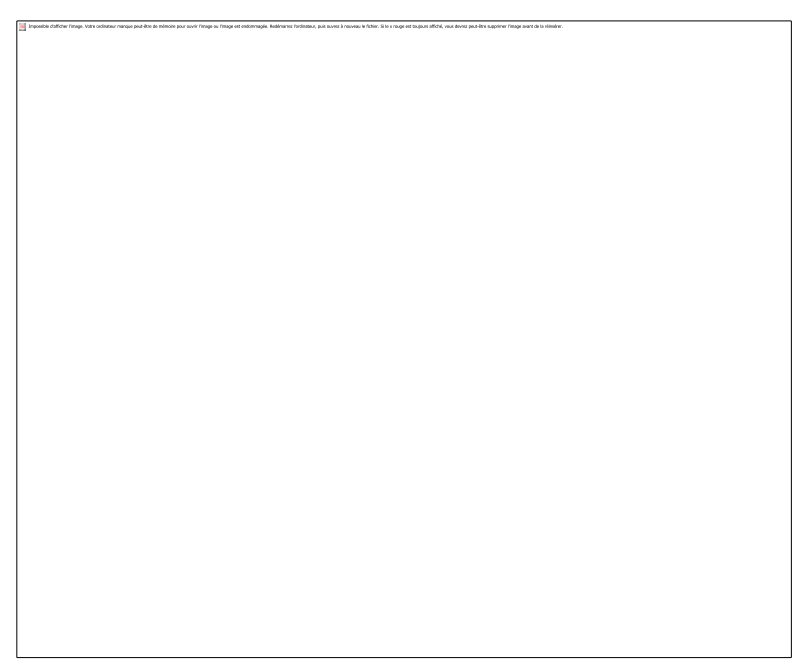

238 Fig. 3. Water activity in the tannin foam as a function of water uptake (after data from [15]). 
240 Since the porous evaporation material is partially filled with water, its average thermal 241 conductivity $\lambda_{m}\left(\mathrm{~W} \mathrm{~m}^{-1} \mathrm{~K}^{-1}\right)$ must be calculated taking into account the thermal conductivities 242 of the material skeleton, water and air:

$$
\lambda_{m}=\lambda_{w} \varepsilon_{l}+\lambda_{s} \varepsilon_{s}+\lambda_{a} \varepsilon_{g}
$$

243 where $\varepsilon_{s}$ is the volume fraction of solid in the porous evaporation material, $\varepsilon_{g}$ is the 244 corresponding volume fraction of gas such that $\varepsilon_{g}=1-\varepsilon_{s}-\varepsilon_{l}$, and $\lambda_{w}, \lambda_{s}$ and $\lambda_{a}\left(\mathrm{~W} \mathrm{~m}^{-1}\right.$

$245 \mathrm{~K}^{-1}$ ) are the thermal conductivities of water, material skeleton and air.

\subsubsection{Heat capacity}

247 The mass heat capacity of the material, $c_{p, m}$, varies much with the presence of water but 248 the effect of air on $c_{p, m}$ can be neglected. Therefore, the volumetric heat capacity was 249 calculated as follows:

$$
\rho_{m} c_{p, m}=\varepsilon_{l} \rho_{w} c_{p, w}+\varepsilon_{s} \rho_{s} c_{p, s}
$$

250 where $\rho_{m}\left(\mathrm{~kg} \mathrm{~m}^{-3}\right)$ and $c_{p, m}\left(\mathrm{~J} \mathrm{~kg}^{-1} \mathrm{~K}^{-1}\right)$ are the density and the mass heat capacity of the 251 simulated material filled with water, respectively, and $c_{p, s}\left(\mathrm{~J} \mathrm{~kg}^{-1} \mathrm{~K}^{-1}\right)$ is the mass heat 252 capacity of the dry, porous, evaporation material.

\section{3}

\subsubsection{Vaporisation enthalpy}

254 The enthalpy of vaporisation of water, $h_{v}\left(\mathrm{~kJ} \mathrm{~kg}^{-1}\right)$, changes slightly with the temperature 255 according to [16]:

$$
h_{v}=1.91846 \times 10^{3}\left(\frac{T}{T-33.91}\right)^{2}
$$


257 Calculated variables $T$ and $\varepsilon_{l}$ were obtained using the commercial software COMSOL 258 Multiphysics 5.6. First, a preliminary parametric study on the triangular mesh was carried out 259 in the first study case (i.e., without insulation) for three meshes comprising 2569 elements 260 (mesh \#1), 2873 elements (mesh \#2), and 5553 elements (mesh \#3). Since the impact of mesh 261 size on the results were extremely limited, mesh \#2 with 2873 elements was used. Fig. 4a 262 shows a mesh consisting of 2873 elements for the first study case and 5431 for the second 263 (Fig. 4b), both refined at the interfaces between water and evaporation material, as well as the 264 interface between air and the evaporation material, with 100 elements. The rest of the mesh is 265 created automatically by the software, depending on the physics involved. Using a desktop 266 computer with a quad-core Xeon E5 coupled with 64 GB of RAM, the model for a system 267 without insulation is calculated in 1 minute and 5 seconds, while the model for a system with 268 insulation around the beaker is calculated in around 1 minute and 40 seconds. The simulation 269 required 90 calculation steps, with a step time self-determined by the software. 


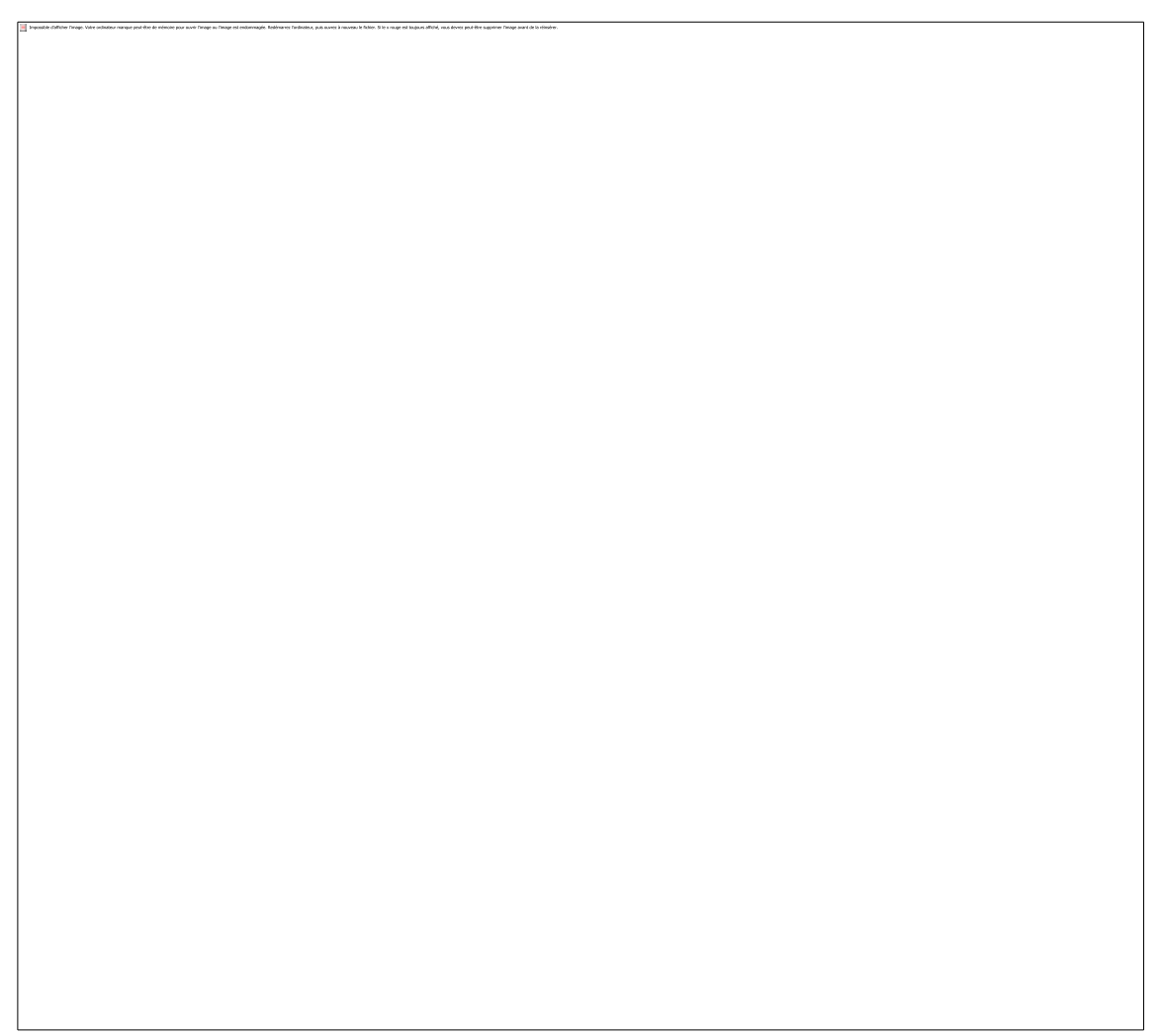

271 Fig. 4. Mesh used for the water evaporation system: (a) without insulation (case 1); and (b)

272 with insulation (case 2).

\section{Results and discussion}

274 In order to validate the numerical model, the results of the calculations were compared 275 with the results of the experiments obtained with the floating tannin-based foam, for the two 276 cases, i.e., with and without insulation foam. Then, different cases from the open literature 277 were examined with the proposed model, and the model was modified if necessary, taking 278 into account the different parameters considered in these former studies. This includes 279 ambient air temperature, relative humidity, solar power density, convection coefficient, and 280 system geometry. Overall, the objective is not to reproduce the same results from the 281 literature but to compare trends. 


\subsection{Validation of the model}

283 Evaporation experiments were conducted without and with insulation (i.e., corresponding 284 to case 1 and 2, respectively) around the beaker containing the floating tannin foam, under 285 different solar inputs. To validate the simulation, the external conditions were imported as 286 input $\left(T_{a}\right.$ and $H_{r}$ ) and the duration was set to that of the experiment. The sunlight power was 287 set to three different values during the same test: 0.7 sun, then 1 sun and finally 1.3 sun, each 288 for a duration of 3300 seconds for the non-insulated configuration and 3500 seconds for the 289 insulated configuration. Changing the illumination in the middle of the test allows the 290 evolution over time of parameters such as temperature and mass loss to be validated when the 291 power input changes. The results of the simulation were compared to the average of three 292 experiments and are shown in Fig. 5.

\subsubsection{Non-insulated configuration}

294 Fig. 5a shows the vertical section of the configuration without insulation, where 1, 2 and 3 295 are the temperature measurement points, and Fig. 5b and Fig. 5c show the experimental and 296 predicted results. 


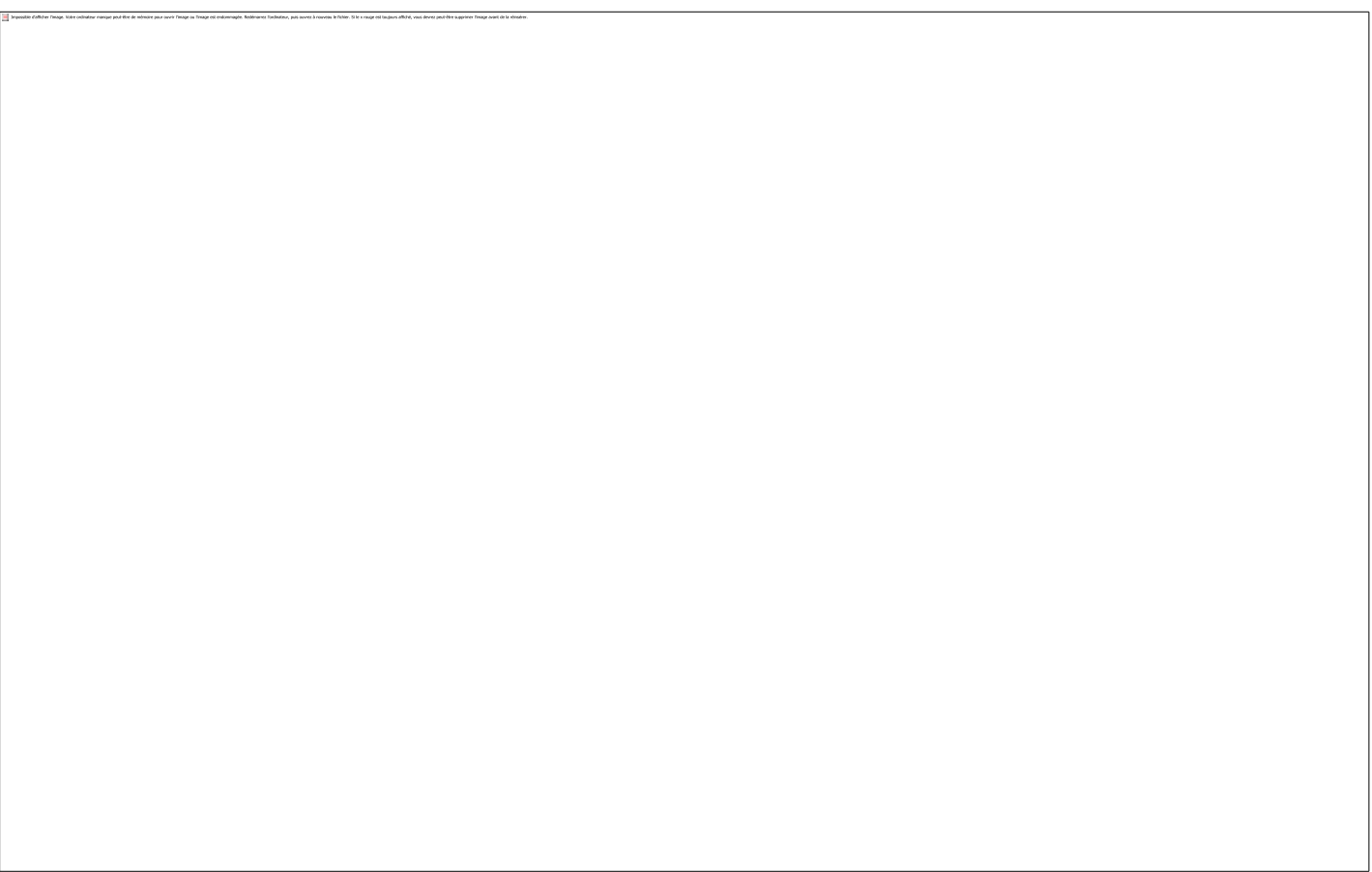

298 Fig. 5. Revolution cross-section of the model water evaporation system in the case where this 299 system is (a) non-insulated, and (d) insulated; experimental (circles) and simulated (lines) 300 temperatures for (b) non-insulated and (e) insulated system; and water mass evolution for the 301 (c) non-insulated, and (f) insulated system.

302 The experimental evaporation rates are equal to $0.51,0.70$ and $1.01 \mathrm{~kg} \mathrm{~m}^{2} \mathrm{~h}^{-1}$ with 303 efficiencies of 49,47 and $52 \%$ for $0.7,1$ and 1.3 sun, respectively. In comparison, the 304 calculated evaporation rates are equal to $0.48,0.74$ and $1.03 \mathrm{~kg} \mathrm{~m}^{2} \mathrm{~h}^{-1}$ with efficiencies of 46 , 30550 and $53 \%$ for $0.7,1$ and 1.3 sun, respectively. The difference between the simulated mass 306 of water and the experimental measurements is no higher than 5\% (see Fig. 5c). The three 307 different solar inputs are clearly visible on the temperature curves, showing three successive 308 jumps. The agreement between measured and calculated temperatures is better in the 309 evaporation material (point 2) and at the interface between the latter and the water (point 3) 310 than at the surface (point 1) (see Fig. 5b). This discrepancy at point 1 is attributed to the 311 setting of the thermal camera (position, emissivity, measurement area) and the estimation of 312 fitted parameters in the model such as the convection coefficient. The average differences 
313 between the simulated and experimental temperatures in the first case study are indeed, from

314 top to bottom, $1.01,0.69$ and $0.44{ }^{\circ} \mathrm{C}$, which shows that the model reproduces the experiment 315 fairly closely.

\subsubsection{Insulated configuration}

Fig. 5d, e and $\mathbf{f}$ are equivalent to Fig. 5a, $\mathbf{b}$ and $\mathbf{c}$, respectively, the only difference being the layer of insulating material around the beaker. The experimental evaporation rates are equal to $0.56,0.82$ and $1.19 \mathrm{~kg} \mathrm{~m}^{2} \mathrm{~h}^{-1}$ with efficiencies of 53,55 and $61 \%$ for $0.7,1$ and 1.3 sun, respectively. In comparison, the calculated evaporation rates are equal to $0.54,0.88$ and $1.25 \mathrm{~kg} \mathrm{~m}^{2} \mathrm{~h}^{-1}$ with efficiencies of 52,59 and $64 \%$ for $0.7,1$ and 1.3 sun, respectively. The average difference between experimental and simulated masses of water is $8 \%$, so it is higher than in the non-insulated configuration. The differences for the three temperatures were 2.71, 1.31 and $0.64{ }^{\circ} \mathrm{C}$ for points 1,2 and 3, respectively (Fig. 5d). As in the previous case (Fig. 5b), and for the same reasons, the difference between experimental and simulated surface temperature is higher (point 1 in Fig. 5d) than for the other two temperatures, in the bulk (point 2) and at the interface (point 3), which were recorded with thermocouples. However, the evolution of the water mass over time is fairly well predicted by the model for the three illuminations tested, as well as the transient thermal evolution that occurs when the input 330 sunlight changes.

The numerical model has therefore been validated and we can conclude that it can be used to simulate water evaporation in the following. This validation was done on the basis of the results obtained with tannin foam, but this material did not show particularly interesting performances compared to other materials reported in the literature, and for which the evaporation rate were close to $1.3 \mathrm{~kg} \mathrm{~m}^{-2} \mathrm{~h}^{-1}$ [17]. We now extend the application of this model to these more efficient materials in terms of solar evaporation. 


\subsection{Study of different cases using the model}

Among the large number of evaporation results for different materials and systems in the literature, some phenomena and techniques are discussed repeatedly. The aim of this section is to test the behaviour of our model when applied to the cases seen in the literature. Those cases can be a good source of inspiration for the design of an efficient evaporation system. For all studies considered, unless otherwise specified, the temperature of the air was set at 20 ${ }^{\circ} \mathrm{C}$ with a relative humidity $\left(H_{R}\right)$ of $50 \%$. The initial temperature of all components was also set at $20^{\circ} \mathrm{C}$.

\subsubsection{Impact of ambient conditions}

The previous section 4.1.2 has shown the significant impact of the beaker insulation on the system performance, which indicates a dependence of the performance on the ambient conditions. In order to better understand their impact, several parametric studies on the exchanges between the air and the material (i.e., air temperature, relative humidity, convection and solar input) were carried out using the numerical model. The evaporation performance was calculated from the final results, which correspond to a steady state.

\subsubsection{Air temperature}

The first parameter that has an impact on the evaporation rate is the ambient air temperature, which can be easily measured and controlled. In the simulation, we set the relative humidity at $50 \%$ with natural convection, and a parametric study was conducted on the air temperature.

Fig. 6a shows the simulated evaporation rates for different values of air temperature, and the corresponding evaporation efficiency. With increasing temperature, the evaporation rate increases significantly, leading to changes of about $0.15 \mathrm{~kg} \mathrm{~m}^{-2} \mathrm{~h}^{-1}$ and $10 \%$ efficiency for a temperature change of $10{ }^{\circ} \mathrm{C}$, which may be a reasonable change over a whole day. 
Evaporation in the dark is also likely to change, as it is also shown in the same figure for three different temperatures (taken from [4]).

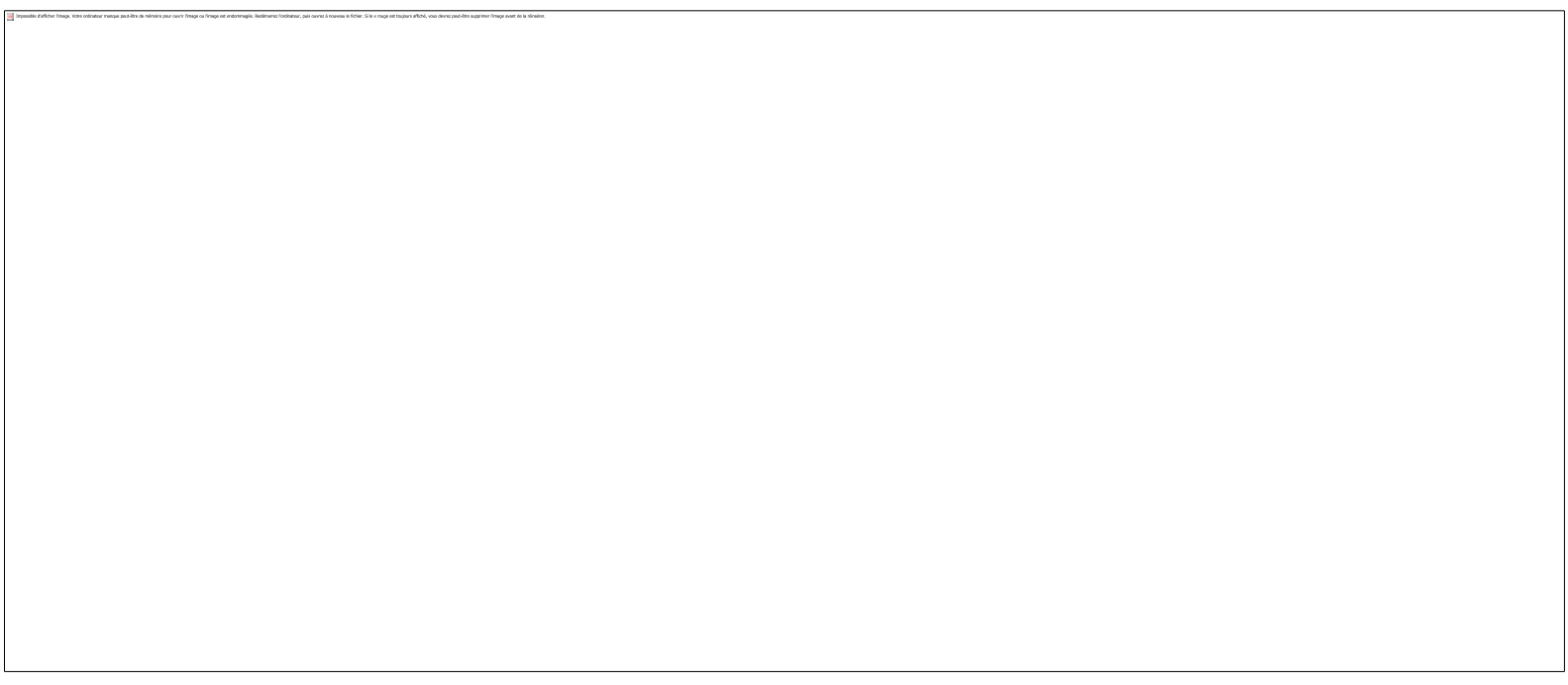

Fig. 6. Simulated evaporation rate as a function of: (a) air temperature at $50 \% \mathrm{H}_{R}$, with the corresponding experimental evaporation in the dark (taken from [4]); and (b) relative humidity of the air at $20^{\circ} \mathrm{C}$. In each case, some data of experimental evaporation rate in the dark are also given: (a) at 3 different temperatures at $50 \% H_{R}$; and (b) at 3 different $H_{R}$ at 23.6 ${ }^{\circ} \mathrm{C}$ (from [4]).

\subsubsection{Relative humidity}

The relative humidity $\left(H_{R}\right)$ is considered in Eq. 11 and it also has an impact on the evaporation rate at $20{ }^{\circ} \mathrm{C}$, which was studied by varying the $H_{R}$ from 10 to $90 \%$, with a $10 \%$ step. Fig. 6b shows the evaporation rate and efficiency as a function of $H_{R}$. Lower $H_{R}$ increases the evaporation rate and efficiency, for instance the evaporation rate increases from

$3740.60 \mathrm{~kg} \mathrm{~m}^{-2} \mathrm{~h}^{-1}$, with an efficiency of $40 \%$ at $90 \% H_{R}$, to $0.72 \mathrm{~kg} \mathrm{~m}^{-2} \mathrm{~h}^{-1}$, with an efficiency of $49 \%$ at $10 \% H_{R}$. Although $H_{R}$ is a factor that has a significant impact on evaporation rate and

376 efficiency, it is easier to control and can simply be recorded as an ambient parameter. The 377 effect of $H_{R}$ at $23.6^{\circ} \mathrm{C}$ on the evaporation rate in the dark is also plotted for three $H_{R}$ values 378 for reference (from [4]). 


\subsubsection{Heat exchange with air by convection}

Insulating the system increases evaporation performance by increasing the temperature and

381 thus the evaporation rate [18], as shown when validating our model in section 4.1.2. Although

382 convection increases the heat exchange of the system with the air [19], which means that there

383 is more heat loss (Eq. 4, Eq. 14 and Eq. 16), convection also increases the evaporation rate $F_{m}$

384 (Eq. 11 and Eq. 12) with or without solar illumination. Here, three types of forced convection,

385 with and without insulation, are tested by adjusting the convection coefficients to three air

386 flow rates. These three flow rates are $0.15,0.30$ and $0.6 \mathrm{~m} \mathrm{~s}^{-1}$ which corresponds to a heat

387 exchange coefficient at the evaporation surface $h_{c}$ of $6.8,9$ and $12.4 \mathrm{~W} \cdot \mathrm{m}^{-2} \cdot \mathrm{K}^{-1}$. Fig. 7 shows

388 the surface evaporation rates in the dark and under 1 sun illumination with their

389 corresponding efficiencies as a function of the air flow rate, with and without insulation

390 around the beaker. 
a)

WITHOUT INSULATION

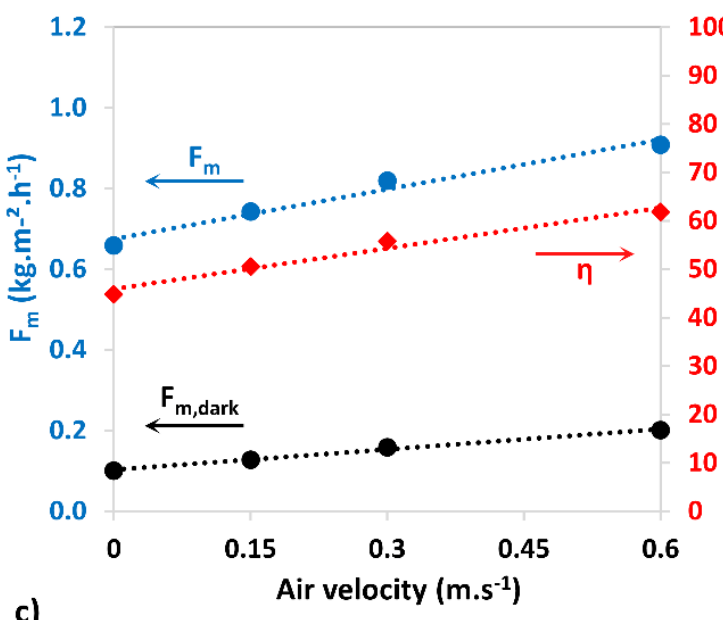

c)

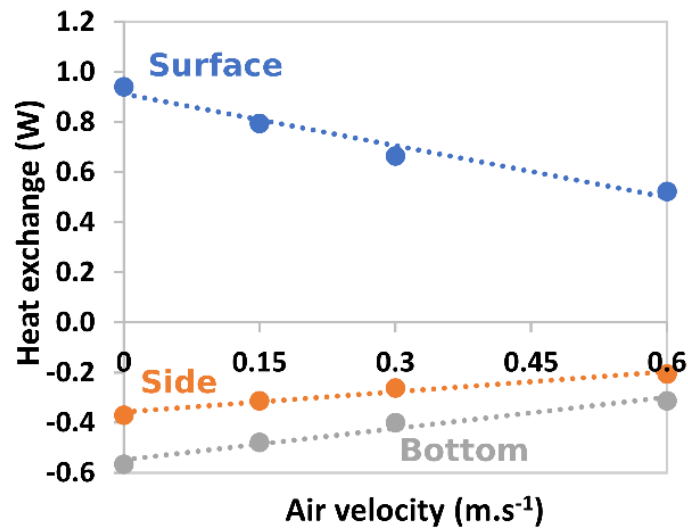

b)

WITH INSULATION
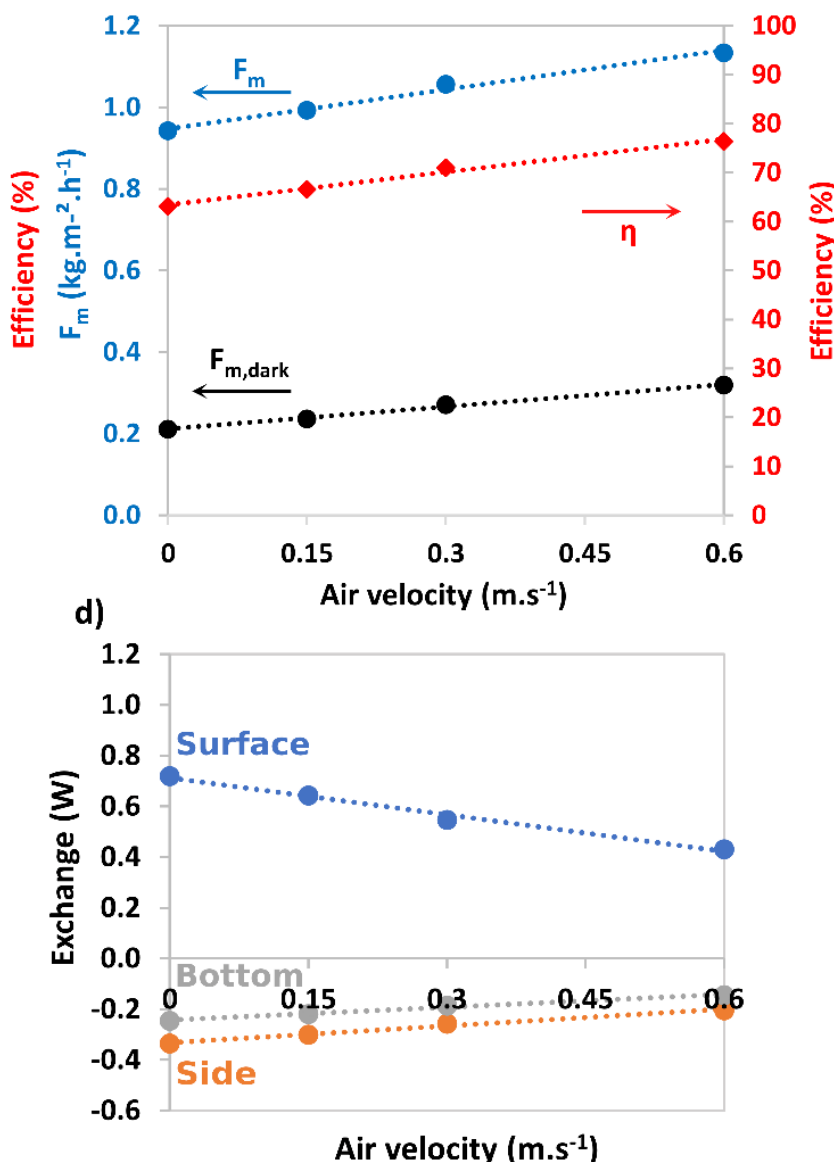

Fig. 7. Simulated evaporation rate: (a) without, and (b) with insulation for several air

393 velocities. $F_{m, \text { dark }}$ and $F_{m}$ are evaporation rates in the dark and under 1 sun, respectively.

394 Heat exchange flux (such that losses take negative values) at different material surfaces: (c)

395 without and (d) with insulation, as a function of air velocity.

Forced convection improves water evaporation performance in the dark and in the light,

397 which means that although heat loss increases with convection, the evaporation rate benefits

398 more. Insulation around the beaker also improves evaporation in darkness and light. Despite

399 slightly reducing the slope of the trend line (compare Fig. 7b and Fig. 7a), beaker insulation

400 gives the same results by increasing convection. As shown in Fig. 1c and Fig. 7d, the

401 insulation reduces the amount of heat exchange between the material and the bulk water as

402 well as between the material and its side, which is divided by 3 in the insulated case. The 
403 global heat exchange between the air and the evaporation surface is lower in the insulated 404 case than in the non-insulated case. Considering that the solar input is the same, this is 405 consistent with the evaporation results. The more water evaporates, the more heat is 406 transferred to the air, and the less heat reaches the material surface. Overall, insulation can 407 only reduce the heat loss from the sides of the beaker, , which does not have as much impact 408 on evaporation as convection at the surface of the material. Nevertheless, convection may 409 improve evaporation in a large open area when a much larger evaporation surface is used, so 410 it is an interesting factor to consider when evaluating evaporation performance.

\section{$411 \quad$ 4.2.1.4 Solar power and efficiency}

412 One of the most mentioned phenomena in the literature is the increase in evaporation 413 efficiency with increasing solar energy [20,21]. Many papers show results with illuminations 414 above 1 sun as solar energy input [22-28]. Fig. 8 shows evaporation rate and efficiency 415 results from the literature as a function of solar power concentration. The more power there is 416 on the WES, the higher is the efficiency. 
418 Fig. 8 Evaporation rates (E.R.) and evaporation efficiencies for different solar concentrations,

419 as reported in the literature: (a) and (c) for a wood-based material [20] (reproduced from Ref.

420 [20] Copyright (2017), with permission from Wiley); and (b) and (d) for an improved 421 bamboo-based material [21] (reproduced from Ref. [21] Copyright (2020), with permission 422 from Elsevier).

423 Based on these articles, Fig. 9a shows the simulated evaporation rate and efficiency for our 424 system. The efficiency increases from 49 to $67 \%$ when the illumination increases from 1 to 7 425 sun and so the evaporation rate increases from 0.7 to $6.9 \mathrm{~kg} \mathrm{~m}^{-2} \mathrm{~h}^{-1}$. It is important to note 426 that, according to Eq. 1, if the efficiency had remained constant, the evaporation rate at 7 suns 427 would have been $4.9 \mathrm{~kg} \mathrm{~m}^{-2} \mathrm{~h}^{-1}$ (only 7 times the evaporation at 1 sun). With a $15 \%$ increase 428 in efficiency from 1 to 7 sun for our system, Fig. 8c showing a $12 \%$ increase and Fig. 8d a 14 
432 Fig. 9 (a) Simulated evaporation rate and simulated efficiency for different solar 433 illuminations. (b) Evolution of the simulated evaporation rate $F_{m}$ with surface temperature, 434 according to Eq. 11 and Eq. 13 (blue line), with the results of temperature and evaporation 435 rate at different solar illuminations (black dots).

436 Natural convection alone cannot be the only cause of the increase in efficiency and, 437 although the enthalpy of vaporisation also changes with the temperature according to Eq. 20, 438 it produces only a slight increase in the evaporation rate. The main cause of the increase in 439 efficiency is the surface temperature, which increases steadily with increasing illumination. 440 As $P_{w}^{v, s a t}$ is a function of temperature (Eq. 13), the latter plays a major role in the evaporation 441 rate (Eq. 11). Fig. 9b shows that the evaporation rate increases exponentially with surface 442 temperature while it increased linearly with illumination (Fig. 9a).

\subsubsection{Increase of the exchange area with air}

444 Several studies have shown that increasing the evaporation area effectively increases the 445 performance of the system [4,7,29]. One of its consequences is a decrease in surface 
temperature, due to the fact that sunlight is then scattered over a larger area and the exchange

447 with air is higher, thus reducing the local heating and thus the temperature. This technique has

448 already been explored in the literature [4], as shown in Fig. 10, with a carbon-coated paper

449 placed on a polystyrene foam. By increasing the receiving area (Fig. 10d and Fig. 10e) the

450 evaporation rate also increases (Fig. 10c).

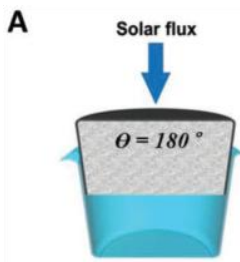

D

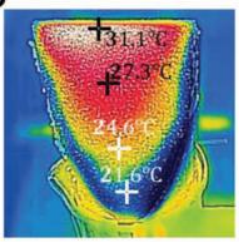

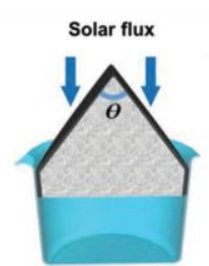

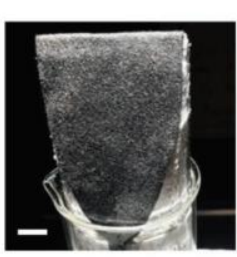

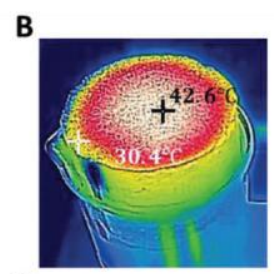

$\mathbf{E}$

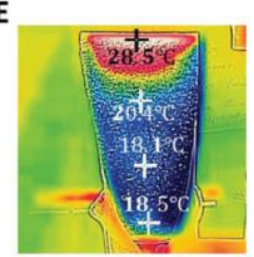

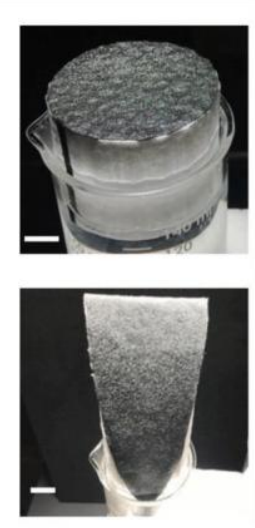
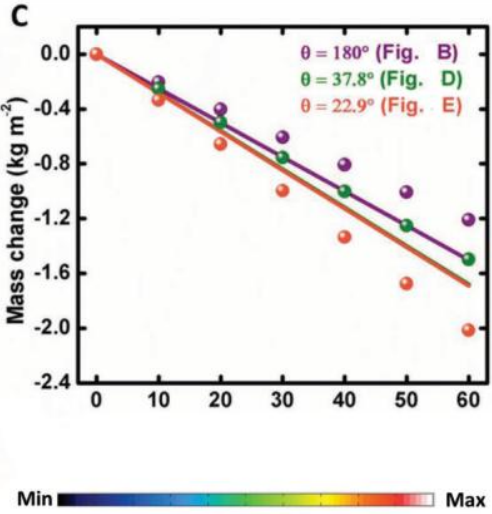

451

Fig. 10 (a) Geometries used in the literature for increasing the exchange area; (b) surface temperature of the flat surface $\left(\theta=180^{\circ}\right)$; (c) experimental evaporation rate for the different surfaces (dots) and the theoretical limit of evaporation at 1 sun (lines); (d) surface temperature when $\theta=37.8^{\circ}$; and (e) surface temperature when $\theta=22.9^{\circ}$. Reproduced from Ref. [4] Copyright (2018).

Based on this work, we have modified the geometry of our model to represent the increase in surface area in the simulation. A conical geometry, not identical but close to the geometry illustrated in Fig. 10a, was chosen for its simplicity to be captured by the axisymmetric model. With such a geometry, we can easily conduct a parametric study on the height of the cone. For that purpose, a variable $N$ has been created, which is written as follows:

$$
N=\frac{h}{r}
$$


462 where $h(\mathrm{~m})$ and $r(\mathrm{~m})$ are the height and the radius of the base of the cone, respectively. This

463 allows the cone height to be easily fixed in the simulation and to produce a parametric study 464 with integer values. The solar power, initially $1 \mathrm{~kW} \mathrm{~m}^{-2}$ at the base of the cone, is decreased 465 when the tip of the cone is stretched as this increases the area. A coefficient $k$ (dimensionless) 466 is defined to account for the corresponding scattering of the solar power. It represents the 467 increase in surface area when changing from a flat surface to a conical surface and is 468 calculated as follows:

$$
k=\frac{S_{\text {base }}}{S_{\text {cone }}}=\frac{\pi r^{2}}{\pi r \sqrt{r^{2}+(N r)^{2}}}=\frac{1}{\sqrt{1+N^{2}}}
$$

469 where $S_{\text {base }}\left(\mathrm{m}^{2}\right)$ is the area of the base of the cone and $S_{\text {cone }}\left(\mathrm{m}^{2}\right)$ is the lateral area of the 470 cone. Therefore, the power concentration at the surface of the cone reads:

$$
P_{m}=P_{s, 0} k
$$

471 where $P_{m}\left(\mathrm{~kW} \mathrm{~m}^{-2}\right)$ is the surface solar power arriving on the material, and $P_{s, 0}\left(\mathrm{~kW} \mathrm{~m}^{-2}\right)$ is 472 the surface solar power arriving from the sun. A with the decrease in power concentration, the 473 evaporation rate increased, as the evaporation rate is still determined by the flat surface that 474 receives the sunlight $\left(S_{\text {base }}\right)$. Fig. 11 shows the conical geometry used in the simulation with 475 the parameters introduced previously, for three values of $N$. With the increase of the 476 parameter $N, k$ decreases, which reduces the solar power density. 
478 Fig. 11 Conical geometry used in the simulation, here shown for three parameters $N$ : 0 (flat),

4792 and 3.

480 Fig. 12a shows the simulation results of evaporation rates and efficiencies by varying $N$ 481 from $N=0$ (flat surface) to $N=8$, applying the model presented here. The temperatures are 482 also shown for each simulated cone. It can be observed that the evaporation rate and the 483 efficiency increase linearly with $N$ while the surface temperature decreases. This observation 484 is contrary to the previous study, which showed that the evaporation flux increases with the 485 surface temperature. It can also be observed that the evaporation rate decreases with 486 increasing the area of the cone (Fig. 12b). The calculation of the performance of the system, 487 concerning evaporation, is not related to the exchange area but to the area at the base of the 488 structure. By calculating the flux related to the base, we observe an increase in the evaporated 
489 flux as a function of $N$ and therefore of the exchange area (Fig. 12b). It is also observed that

490 the ratio $1 / k$ between the exchange area and the area at the base increases linearly with $N($ Fig.

491 12c), which shows the direct relationship between the evaporation area and the evaporated

492 flux related to the base of the cone. Overall, the increase in evaporation area is beneficial,

493 since it doubles the efficiency from $N=0$ to 8 , passing from 44 to $88 \%$. It should be noted

494 that these efficiencies were calculated using Eq. 1, which does not take into account the heat

495 exchange with the air, but only the solar illumination input and the evaporation rate output.

496 However, such an improvement could have limitations, for example, a slender geometry

497 with $N=8$ could be difficult to produce. Another possible geometry could be a recessed 498 spherical area, which might be easier to manufacture [30]. With such a geometry, the surface 499 allows the same kind of reduction of heat loss with air, but also a reduction of radiation loss,

500 since the light beam is partially reflected inside the sphere. Such a system could achieve 1.65

$501 \mathrm{~kg} \mathrm{~m}^{-2} \mathrm{~h}^{-1}$ for a solar illumination of 1 sun [30]. 


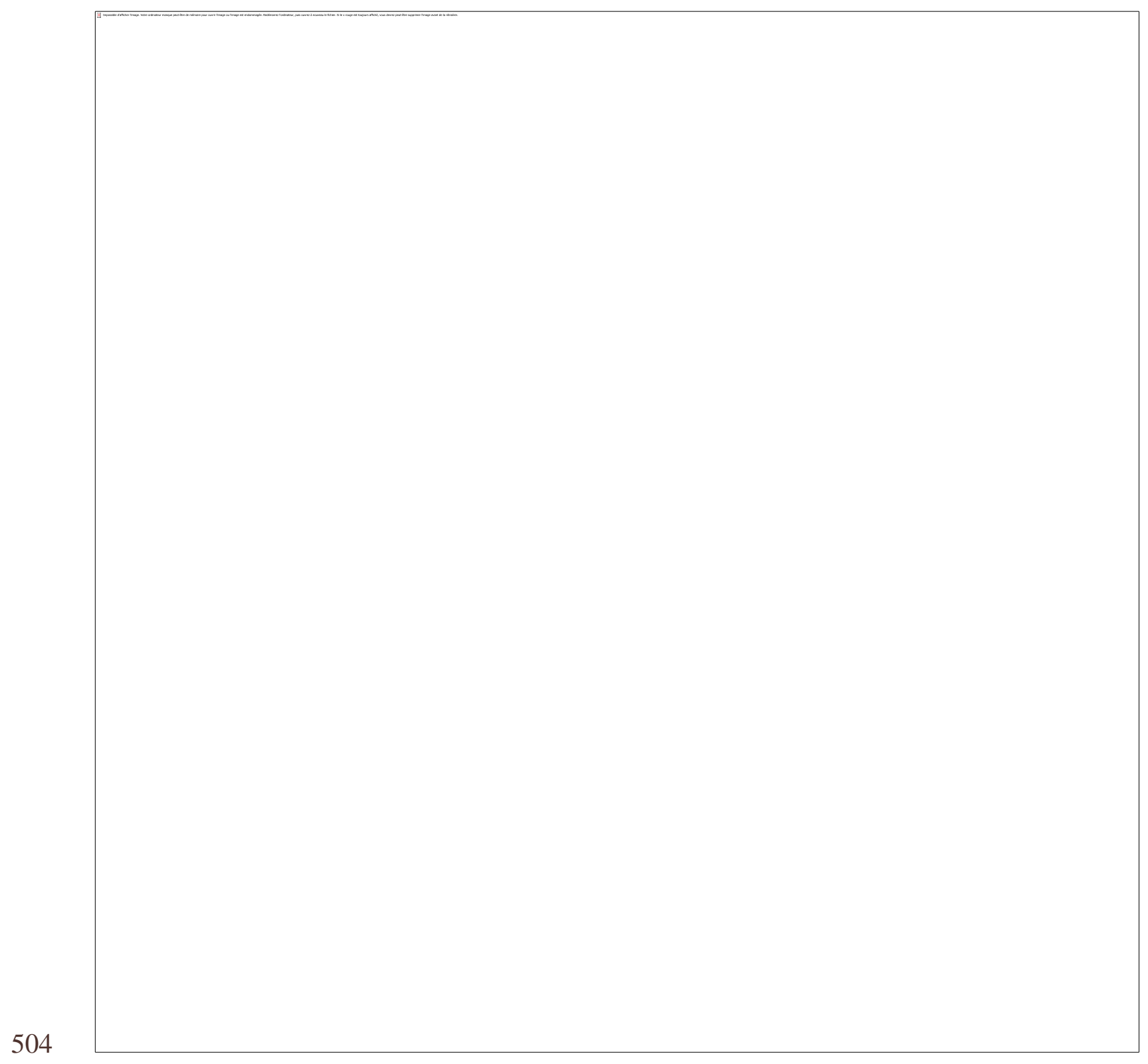

505 Fig. 12. (a) Simulated evaporation rate (left axis) and efficiency (right axis) calculated using 506 Eq. 1, for different values of $N(N=0$ corresponding to a flat surface), and surface 507 temperature (colour bar code) as a function of geometry change; (b) evaporation rate 508 calculated with the base area as a reference and using the cone area as reference; and (c) 509 variations of $k$ and $1 / k$ with the increase of surface area. 


\subsubsection{Insulation under the material}

Due to the natural shape of some materials, it is not possible to use them alone for

512 evaporation and therefore an additional material must be used to maintain the evaporative surface above the water [5,31-35]. This can be a standard foam for thermal insulation, which

514 has the ability to float on water but also allows less heat exchange with water due to its very 515 low thermal conductivity. This was done by $\mathrm{Xu}$ et al. [31], whose system is shown in Fig. 516 13a, where a mushroom was placed on a polystyrene foam support. The path taken by the 517 water to evaporate is in the centre of the insulation foam, where a hole has been made to allow 518 the mushroom to touch the water. Similarly, Fig. 13b shows another type of WES that has 519 paper wrapped around an insulating foam [36] to allow water to be transported through the 520 sides of the system to an evaporation surface at the top.

Fig. 13 (a) Mushroom-based water evaporation system on a floating polyurethane foam support, reproduced with permission from Ref. [31]. Copyright 2017, Wiley-VCH; (b) a WES using paper around an insulation foam, reproduced from Ref. [36]. Copyright (2016), with permission from National Academy of Sciences.

526 Inspired by these two uses of insulating foam, we studied two configurations, one where

527 the insulator is located in the core of the evaporation material, with water transport taking 528 place at the sides, and the other where the insulator is located around the material, with water 
532 Fig. 14. Simulated temperature of the system with the insulation layer located: (a) in the core, 533 with peripheral water transport, and (b) at the periphery, with a central hole for water 534 transport. Both configurations have the same radius and height ratio of the supporting foam to 535 the evaporation material.

Thus, the evaporation material is positioned on the insulating/floating foam, and water transport is allowed either through a central hole or through the periphery. To study the 538 impact of the foam, parametric studies were conducted on the effects of varying the radius $539\left(R_{i}\right)$ and the height $\left(h_{i}\right)$ of the insulating foam. $N_{r}$ and $N_{h}$ represent the ratios of the radius and 540 heights of the foam to those of the evaporation material (see Eq. 24 and Eq. 25 and Fig. 15).

$$
\begin{gathered}
N_{r}=\frac{R_{i}}{R_{t}} \\
N_{h}=\frac{h_{i}}{h_{t}}
\end{gathered}
$$

541 where $R_{t}$ and $h_{t}$ are the radius and the height of the evaporation material, respectively. The

542 higher $N_{h}$ and $N_{r}$, the larger the foam and the more space it takes under the material. $N_{r}=0$ 
543 with $N_{h}=0$ thus correspond to the case without insulation layer. The variations of $N_{r}$ for the 544 two configurations are represented in Fig. 15.

545 Adding an insulation layer under the evaporation material should theoretically improve 546 performance as more heat is retained on the surface. However, the addition of insulation 547 limits the transport of water to the surface, so a balance must be struck between heat and 548 water management. The simulation shows that increasing the size of the insulation, both in 549 radius and in height, increases evaporation to a certain point, where it reaches its maximum, 550 and then water transport limits the performance. The diffusion coefficient of water in the 551 evaporation material plays an important role in the dimensions of the insulation material that 552 can be used. 


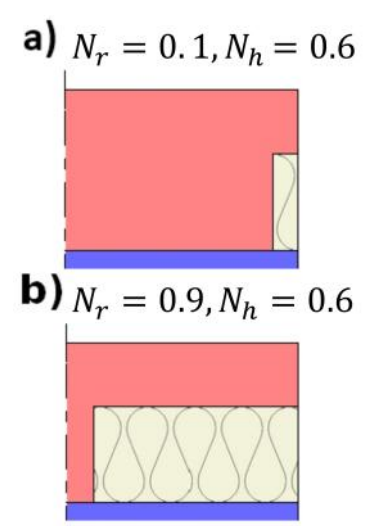

Periphery

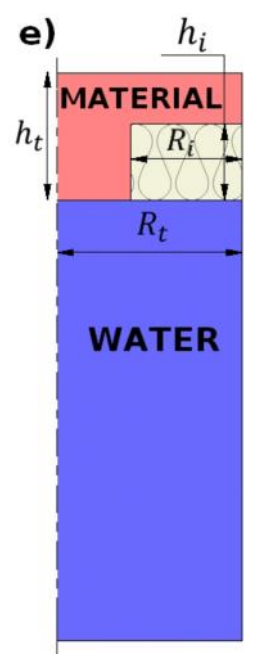

c) $N_{r}=0.1, N_{h}=0.6$
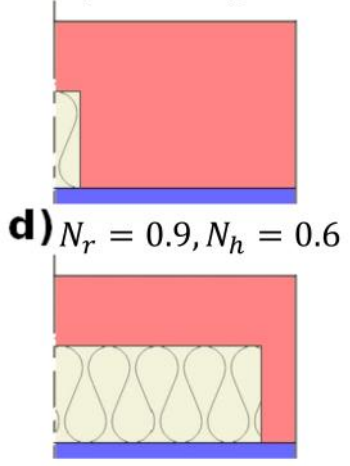

Centre

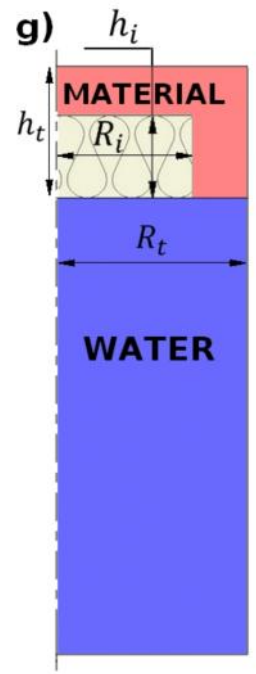

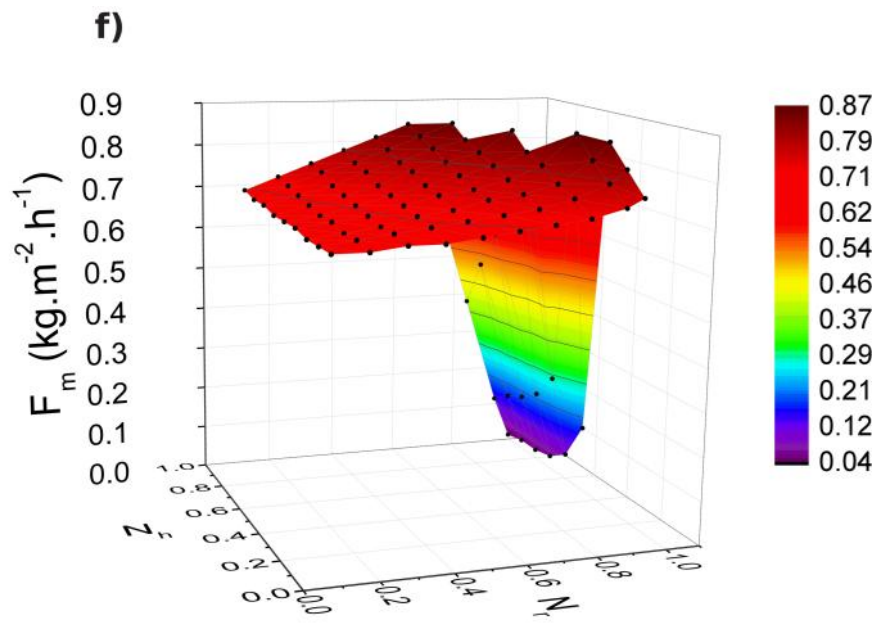

h)

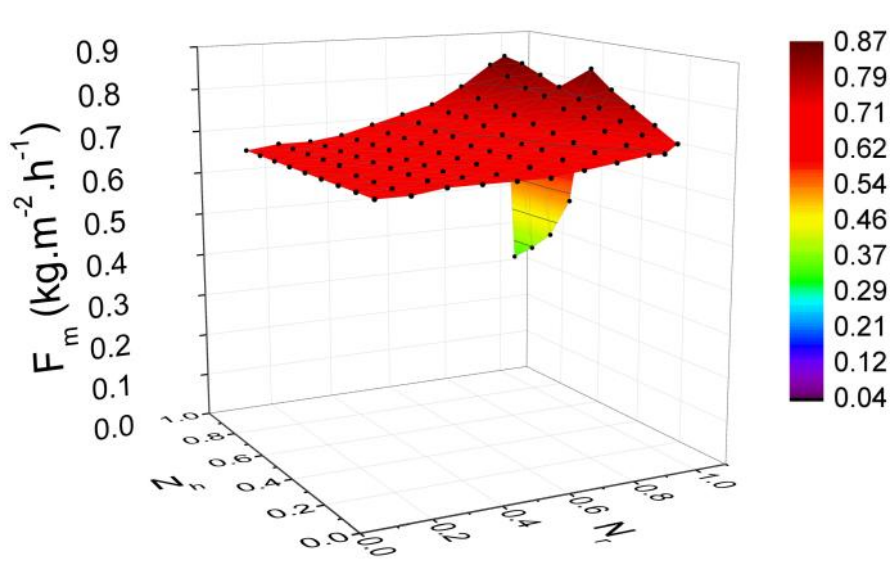

554 Fig. 15. Top: Cross-section of revolution of the evaporation system shown in Fig. 14b with

555 insulation at the periphery for: (a) $N_{r}=0.1$ and $N_{h}=0.6$, and (b) $N_{r}=0.9$ and $N_{h}=0.6$; (e)

556 system with its notations, and (f) results of evaporation rate for different values of $N_{r}$ and $N_{h}$

557 for insulation at the periphery. Bottom: Cross-section of revolution of the evaporation system

558 shown in Fig. 14a for: (c) $N_{r}=0.1$, and $N_{h}=0.6$, and (d) $N_{r}=0.9$ and $N_{h}=0.6$; (g) system

559 and its notations, and (h) results of evaporation rate for different values of $N_{r}$ and $N_{h}$.

Fig. 15a, $\mathbf{b}$ and $\mathbf{e}$ show the simulation performed when insulation at the periphery was

561 considered. Fig. $15 f$ shows the increase in performance with the values of $N_{h}$ and $N_{r}$, up to 562 certain points where the insulation takes up too much space and therefore not enough water 563 can be transported to the upper surface, thus limiting the evaporation rate. Fig. 15c, $\mathbf{d}$ and $\mathbf{g}$ 
564 show the case of insulation in the centre. In this case, as shown in Fig. 15h, increasing the

565 size of the insulating foam in both directions increases the evaporation, and as in the first 566 case, up to a certain maximum after which it no longer increases. However, in this case, the 567 evaporation rate starts to decrease at higher values of $N_{h}$ and $N_{r}$. This is due to the peripheral 568 transport of water, which spreads over a larger area compared to the hole in the centre. 569 Therefore, to obtain the same kind of proportion between the volume of the evaporation 570 material and the volume of the insulator, the radius of the insulating foam must be higher. 571 Nevertheless, this geometry, with a thin layer around the insulator, is limited by the 572 possibilities of preparation. A sheet of paper, like the one presented above, is feasible but a 573 foam-like product like our tannin foam would be impossible to cut so thin. Overall, the 574 peripheral insulation with $N_{\mathrm{r}}=0.9$ and $N_{h}=0.4$ achieves an evaporation rate of $0.87 \mathrm{~kg} \mathrm{~m}^{-2} \mathrm{~h}^{-}$

$575{ }^{1}$, while the central insulation with $N_{\mathrm{r}}=0.95$ and $N_{h}=0.9$ gives $0.85 \mathrm{~kg} \mathrm{~m}^{-2} \mathrm{~h}^{-1}$.

576 These observations may be clues to making evaporation systems more efficient, since the 577 thermal conductivity of evaporation materials is strongly influenced by the amount of water 578 inside their porous structure. Having an additional insulating layer to prevent heat exchange 579 with water results in a higher evaporation rate, when water supply to the surface is not a 580 problem. However, this can also be an obstacle when comparing materials. Again, it is 581 essential to consider the whole system, with all the parameters and appropriate geometry, to 582 study its evaporation efficiency.

\section{Conclusion}

A two-dimensional axisymmetric model, validated for temperature and water mass 586 evolutions by experiments on a solar water evaporation system based on tannin foam, has made it possible to study the impact of different operating parameters on the performance of this type of system. As present, the tannin foam is of no interest in this type of system. This is 
due to the fact that the open porosity of the foam is saturated with water, which considerably

590 limits its insulating properties.

We have shown that air temperature, relative air humidity and the type of air convection

592 around the system all have an impact on the evaporation rate. When the air temperature increases from 20 to $50^{\circ} \mathrm{C}$, the evaporation rate is doubled, while a large change in relative

humidity has very little impact on performance. In addition, a system where the beaker is insulated increases the performance of our material by $15 \%$ on average, and increasing the convection at the evaporation surface significantly increases the evaporated flux. This study on the experimental conditions shows the need to approach the experimental conditions recommended by $\mathrm{Li}$ et al. [10] with the air temperature of $25^{\circ} \mathrm{C}$ and the relative air humidity of less than $60 \%$, all in a breeze-free environment. Additionally, the cone study shows that increasing the exchange area allows the evaporation rate of the system to be increased, which is a considerable potential improvement for future development.

Finally, the addition of a thermal insulation layer to the evaporation material, with two possible positions for the water transport channel, either at the centre or at the periphery of the axisymmetric system, proved effective, providing good thermal insulation to prevent energy from going to the water while not impeding water transport. With thermal insulation at the periphery, $N_{r}$ of 0.9 and $N_{h}$ of 0.4 are the best parameters, while $N_{r}$ of 0.95 and $N_{h}$ of 0.9 is the optimal combination when the insulation is in the centre of the system.

\section{Acknowledgements}

This study was supported by the TALiSMAN project, funded by ERDF (2019-000214). 


\section{References}

613 [1] F. Zhao, Y. Guo, X. Zhou, W. Shi, G. Yu, Materials for solar-powered water

614

615

616

617

618

619

620

621

622

623

624

625

626

627

628

629

630

631

632

633

634

635

636

637

638

639

640

641

642

643

644

645

646

647

648

649

650

651

652 evaporation, Nat. Rev. Mater. (2020) 1-14. https://doi.org/10.1038/s41578-020-0182-4.

[2] P. Zhang, Q. Liao, H. Yao, Y. Huang, H. Cheng, L. Qu, Direct solar steam generation system for clean water production, Energy Storage Mater. 18 (2019) 429-446. https://doi.org/10.1016/j.ensm.2018.10.006.

[3] Y. Kuang, C. Chen, S. He, E.M. Hitz, Y. Wang, W. Gan, R. Mi, L. Hu, A HighPerformance Self-Regenerating Solar Evaporator for Continuous Water Desalination, Adv. Mater. 31 (2019) 1900498. https://doi.org/10.1002/adma.201900498.

[4] H. Song, Y. Liu, Z. Liu, M.H. Singer, C. Li, A.R. Cheney, D. Ji, L. Zhou, N. Zhang, X. Zeng, Z. Bei, Z. Yu, S. Jiang, Q. Gan, Cold Vapor Generation beyond the Input Solar Energy Limit, Adv. Sci. 5 (2018) 1800222. https://doi.org/10.1002/advs.201800222.

[5] C. Zhang, P. Xiao, F. Ni, L. Yan, Q. Liu, D. Zhang, J. Gu, W. Wang, T. Chen, Converting Pomelo Peel into Eco-Friendly and Low-Consumption Photothermic Biomass Sponge Towards Multifunctional Solar-to-Heat Conversion, ACS Sustain. Chem. Eng. (2020). https://doi.org/10.1021/acssuschemeng.0c00681.

[6] Q. Zhang, L. Ren, X. Xiao, Y. Chen, L. Xia, G. Zhao, H. Yang, X. Wang, W. Xu, Vertically aligned Juncus effusus fibril composites for omnidirectional solar evaporation, Carbon. 156 (2020) 225-233. https://doi.org/10.1016/j.carbon.2019.09.067.

[7] L. Wu, Z. Dong, Z. Cai, T. Ganapathy, N.X. Fang, C. Li, C. Yu, Y. Zhang, Y. Song, Highly efficient three-dimensional solar evaporator for high salinity desalination by localized crystallization, Nat. Commun. 11 (2020) 1-12. https://doi.org/10.1038/s41467020-14366-1.

[8] F. Zhao, X. Zhou, Y. Shi, X. Qian, M. Alexander, X. Zhao, S. Mendez, R. Yang, L. Qu, G. Yu, Highly efficient solar vapour generation via hierarchically nanostructured gels, Nat. Nanotechnol. 13 (2018) 489-495. https://doi.org/10.1038/s41565-018-0097-z.

[9] Y. Guo, H. Lu, F. Zhao, X. Zhou, W. Shi, G. Yu, Biomass-Derived Hybrid Hydrogel Evaporators for Cost-Effective Solar Water Purification, Adv. Mater. 32 (2020) 1907061. https://doi.org/10.1002/adma.201907061.

[10] X. Li, G. Ni, T. Cooper, N. Xu, J. Li, L. Zhou, X. Hu, B. Zhu, P. Yao, J. Zhu, Measuring Conversion Efficiency of Solar Vapor Generation, Joule. 3 (2019) 1798-1803. https://doi.org/10.1016/j.joule.2019.06.009.

[11] G. Tondi, V. Fierro, A. Pizzi, A. Celzard, Tannin-based carbon foams, Carbon. 47 (2009) 1480-1492. https://doi.org/10.1016/j.carbon.2009.01.041.

[12] Z. Marie, V. Nicolas, A. Celzard, V. Fierro, First approach for modelling the physical foaming of tannin-based thermoset foams, Int. J. Therm. Sci. 149 (2020) 106212. https://doi.org/10.1016/j.ijthermalsci.2019.106212.

[13] Y. CENGEL, Heat Transfer a practical approach, Second Edition, 2002.

[14] V. Nicolas, F. Vanin, D. Grenier, T. Lucas, C. Doursat, D. Flick, Modeling bread baking with focus on overall deformation and local porosity evolution, AIChE J. 62 (2016) 3847-3863. https://doi.org/10.1002/aic.15301. 
[15] C. Delgado-Sánchez, M. Letellier, V. Fierro, H. Chapuis, C. Gérardin, A. Pizzi, A. Celzard, Hydrophobisation of tannin-based foams by covalent grafting of silanes, Ind. Crops Prod. 92 (2016) 116-126. https://doi.org/10.1016/j.indcrop.2016.08.002.

[16] B. Henderson- Sellers, A new formula for latent heat of vaporization of water as a function of temperature, Q. J. R. Meteorol. Soc. 110 (1984) 1186-1190. https://doi.org/10.1002/qj.49711046626.

[17] R. Fillet, V. Nicolas, V. Fierro, A. Celzard, A review of natural materials for solar evaporation, Sol. Energy Mater. Sol. Cells. 219 (2021) 110814. https://doi.org/10.1016/j.solmat.2020.110814.

[18] Y. Wang, X. Wu, X. Yang, G. Owens, H. Xu, Reversing heat conduction loss: Extracting energy from bulk water to enhance solar steam generation, Nano Energy. 78 (2020) 105269. https://doi.org/10.1016/j.nanoen.2020.105269.

[19] S. Ali, S.A.U. Rehman, H.-Y. Luan, M.U. Farid, H. Huang, Challenges and opportunities in functional carbon nanotubes for membrane-based water treatment and $\begin{array}{llllll}\text { desalination, } & \text { Sci. Total Environ. } 646 & \text { (2019) 1126-1139. }\end{array}$ https://doi.org/10.1016/j.scitotenv.2018.07.348.

[20] C. Sheng, N. Yang, Y. Yan, X. Shen, C. Jin, Z. Wang, Q. Sun, Bamboo decorated with plasmonic nanoparticles for efficient solar steam generation, Appl. Therm. Eng. 167 (2020) 114712. https://doi.org/10.1016/j.applthermaleng.2019.114712.

[21] C. Chen, Y. Li, J. Song, Z. Yang, Y. Kuang, E. Hitz, C. Jia, A. Gong, F. Jiang, J.Y. Zhu, B. Yang, J. Xie, L. Hu, Highly Flexible and Efficient Solar Steam Generation Device, Adv. Mater. 29 (2017) 1701756. https://doi.org/10.1002/adma.201701756.

[22] Q. Jiang, L. Tian, K.-K. Liu, S. Tadepalli, R. Raliya, P. Biswas, R.R. Naik, S. Singamaneni, Bilayered Biofoam for Highly Efficient Solar Steam Generation, Adv. Mater. 28 (2016) 9400-9407. https://doi.org/10.1002/adma.201601819.

[23] M. Zhu, Y. Li, F. Chen, X. Zhu, J. Dai, Y. Li, Z. Yang, X. Yan, J. Song, Y. Wang, E. Hitz, W. Luo, M. Lu, B. Yang, L. Hu, Plasmonic Wood for High-Efficiency Solar Steam

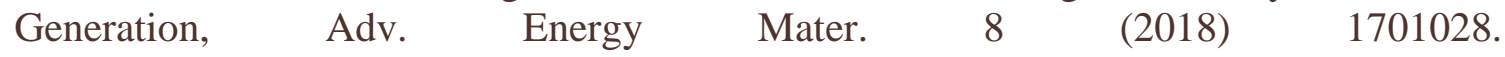
https://doi.org/10.1002/aenm.201701028.

[24] M. Zhu, Y. Li, G. Chen, F. Jiang, Z. Yang, X. Luo, Y. Wang, S.D. Lacey, J. Dai, C. Wang, C. Jia, J. Wan, Y. Yao, A. Gong, B. Yang, Z. Yu, S. Das, L. Hu, Tree-Inspired Design for High-Efficiency Water Extraction, Adv. Mater. 29 (2017) 1704107. https://doi.org/10.1002/adma.201704107.

[25] Z. Li, M. Zheng, N. Wei, Y. Lin, W. Chu, R. Xu, H. Wang, J. Tian, H. Cui, Broadbandabsorbing WO3-x nanorod-decorated wood evaporator for highly efficient solar-driven interfacial steam generation, Sol. Energy Mater. Sol. Cells. 205 (2020) 110254. https://doi.org/10.1016/j.solmat.2019.110254.

[26] M.M. Ghafurian, H. Niazmand, E. Ebrahimnia-Bajestan, R.A. Taylor, Wood surface treatment techniques for enhanced solar steam generation, Renew. Energy. 146 (2020) 2308-2315. https://doi.org/10.1016/j.renene.2019.08.036.

[27] Z. Yu, S. Cheng, C. Li, Y. Sun, B. Li, Enhancing efficiency of carbonized wood based solar steam generator for wastewater treatment by optimizing the thickness, Sol. Energy. 193 (2019) 434-441. https://doi.org/10.1016/j.solener.2019.09.080. 
[28] N.S. Lewis, D.G. Nocera, Powering the planet: Chemical challenges in solar energy utilization, Proc. Natl. Acad. Sci. U. S. A. 103 (2006) 15729-15735. https://doi.org/10.1073/pnas.0603395103.

[29] S.-L. Wu, H. Chen, H.-L. Wang, X. Chen, H.-C. Yang, S.B. Darling, Solar-driven evaporators for water treatment: challenges and opportunities, Environ. Sci. Water Res. Technol. 7 (2021) 24-39. https://doi.org/10.1039/D0EW00725K.

[30] S. Li, Y. He, Y. Wang, D. Liao, H. Liu, L. Zhou, C. Wei, C. Yu, Y. Chen, Simple Hierarchical Interface Design Strategy for Accelerating Solar Evaporation, Macromol. Mater. Eng. n/a (n.d.) 2000640. https://doi.org/10.1002/mame.202000640.

[31] N. Xu, X. Hu, W. Xu, X. Li, L. Zhou, S. Zhu, J. Zhu, Mushrooms as Efficient Solar Steam-Generation Devices, Adv. Mater. $29 \quad$ (2017) 1606762. https://doi.org/10.1002/adma.201606762.

[32] Z. Lin, T. Wu, J. Shi, B. Zhou, C. Zhu, Y. Wang, R. Liang, M. Mizuno, Poly(Nphenylglycine)-Based Bioinspired System for Stably and Efficiently Enhancing Solar Evaporation, ACS Sustain. Chem. Eng. 9 (2021) 448-457. https://doi.org/10.1021/acssuschemeng.0c07608.

[33] Y. Liao, J. Chen, D. Zhang, X. Wang, B. Yuan, P. Deng, F. Li, H. Zhang, Lotus leaf as solar water evaporation devices, Mater. Lett. 240 (2019) 92-95. https://doi.org/10.1016/j.matlet.2018.12.133.

[34] M. Zhu, A. Xia, Q. Feng, X. Wu, C. Zhang, D. Wu, H. Zhu, Biomass Carbon Materials for Efficient Solar Steam Generation Prepared from Carbonized Enteromorpha Prolifera, Energy Technol. n/a (2019) 1901215. https://doi.org/10.1002/ente.201901215.

[35] X. Wang, C. Sha, W. Wang, Y. Chen, Y. Yu, D. Fan, Functionalized biomass-derived composites for solar vapor generation, Mater. Res. Express. 6 (2019) 125613. https://doi.org/10.1088/2053-1591/ab586e.

[36] X. Li, W. Xu, M. Tang, L. Zhou, B. Zhu, S. Zhu, J. Zhu, Graphene oxide-based efficient and scalable solar desalination under one sun with a confined 2D water path, Proc. Natl. Acad. Sci. 113 (2016) 13953-13958. https://doi.org/10.1073/pnas.1613031113. 